\title{
THE IMPORTANCE OF CORPORATE SOCIAL RESPONSIBILITY FOR THE TODAY'S CONSUMER: OPINIONS OF CONSUMERS AND EXPERTS
}

\author{
Toms Kreicbergs, Mg.oec.; Modrite Pelse, Dr.oec. \\ Faculty of Economics and Social Development, Latvia University of Life Sciences and Technologies
}

\begin{abstract}
This research examines the necessity of Corporate Social Responsibility for the today's consumer. It analyses studies conducted in the field of CSR with a thorough literature review and compares them to the results gathered from in-depth interviews with experts of CSR field that follow the tendencies of the consumer's needs and execute CSR strategy and campaigns, as well as the results from a focus groups with consumers.

The research found that consumers are quite sceptical and cynical toward some of the CSR campaigns that they found not to be genuine but rather solely based on profit or covering up social irresponsibility on the behalf of the company. However, when the CSR is embedded at the core of the brand consumers find CSR very compelling and appreciate it greatly, that results in customer loyalty and willingness to share the story about company's CSR efforts further.
\end{abstract}

Key words: Corporate Social Responsibility (CSR), sustainability, consumers, the environment. JEL code: $A 10, M 2$.

\section{Introduction}

Corporate Social Responsibility is defined as the voluntary actions that a corporation implements as it pursues its mission and fulfills its perceived obligations to stakeholders, including employees, the environment, communities, and society as a whole (Coombs W., et al., 2012). The true meaning of CSR is being interpreted depending on who is being asked. For instance, from the right wing politicians, CSR is often viewed as a violation of the principles of free enterprise and confusion of the private and governmental, and nonprofit sectors. However, from the left wing politicians and ideological supporters, CSR is viewed as the best public relations strategy for complacency and control (May S., 2007). Those who favour the free market and the profit view of corporations, might view CSR as decreasing competitiveness, while those who support the business case of CSR favour CSR as increasing competitiveness (Coombs W., et al., 2012). It is also stated that the greatest strength and weakness of CSR is that it can cover so many different issues and be enacted in so many different ways. CSR can cover concerns as diverse as worker rights, environmental preservation, clean energy, water rights, child labour, HIV prevention and treatment, disaster relief, and treatment of indigenous people, to name but a few (Coombs W., et al., 2012).

More importantly for marketing purposes, it has to be discussed that CSR is definitely becoming a key component in a company's marketing mix (Mogele B., 2010). Companies have been looking almost continuously for powerful links and relevant bridging modules for attracting the readers' attention on the one hand and for providing relevant information conveying a high degree of credibility through their CSR commitment on the other hand (ibid). Therefore the aim of this research is to analyse whether the interest for corporations into becoming more socially responsible is justified or not. Thus, the authors identified three key tasks for this research: conducting a study examining what do consumers think about CSR by 1 ) interviewing consumers during a focus group and 2) interviewing experts in the CSR field as well as 3) conducing a thorough literature review.

\section{Research results and discussion}

By examining the appropriate literature, the task was to determine whether the companies truly invest into their CSR efforts and has the scientific community found it to be true that consumers value CSR and prefer brands who are socially responsible. Therefore, the literature review was mostly focused on the importance of CSR for the consumer and from competition point of view. 
Studies show that a popular form of CSR initiative that consumers appreciate is corporate philanthropy, where a company supports a social cause or non-profit organization through sponsorships - typically in the form of profit and/or resource donations. Through such philanthropic initiatives, organizations can positively enhance their corporate image among their stakeholders, which in turn can yield tangible returns (e.g. higher profitability) and/or intangible benefits (e.g. positive attitude towards the firm and its brands; enhanced loyalty) (Sohn Y., et al., 2012). A similar opinion is expressed in Watt's 2010 study, which states that sponsorship continues to evolve and take an ever-more important role in the overall marketing and positioning of companies and brands. Its greatest objective is to engage audiences and communicate more relevant messages personally to more targeted audiences. This means a move away from the media rights-based model towards more value-based partnerships between sponsors and rights holders. Leverage activities will be more thematic, more authentic and aligned to engaging more targeted communities. Hence, there is an opportunity for the integration of CSR and sponsorship strategy and implementation (Watt K., 2010).

Globally, consumers are demanding a higher level of Corporate Social Responsibility (Diehl S., et al., 2016). It is fair to say that Corporate Social Responsibility is becoming more interesting and profiTable for companies to be engaged in, because supply has to meet the demand. From a competition standpoint, which also exemplifies how relevant CSR has become, studies find that companies show commitment to minimizing or eliminating any harmful effects and maximizing [their] long-run beneficial impact on society (Vanhamme J., et al., 2015).

There are also indications, for example, that consumers will switch from one brand to another of same price and quality if the other brand is associated with a cause. In 1999 a survey found that 65 percent on consumers would switch under such conditions versus 87 percent of consumers in 2007 (Mirvis P., 2008). So this tendency of consumers preferring companies being socially responsible is becoming higher and higher.

There are, however, some data pointing to the opposite side of this discussion- that the gain from CSR or the importance of it is rather overrated. For instance, the UN's environmental program describes a 40/4 gap where 40 percent of consumers say they want to buy green product but only 4 percent regularly do, at least as of 2004 when the report was issued (Mirvis P., 2008). There is, not surprisingly, considerable debate about the gap between people's expressed interest and actual buying behaviour in these regards, and certainly as to whether consumers will pay a premium for such goods and services. Claims that consumers will pay 5 percent more for brands from socially responsible companies simply don't bear out in some cases as evident by this study. (Mirvis P., 2008). Therefore one could make the argument that while the consumers do appreciate CSR, they are not willing to pay more for it, which bears asking what is the point of companies being socially responsible, when the consumer is not willing to pay even a little bit more.

As some other studies have pointed out, the reason for that might be the fact that consumers are cynical towards companies being socially responsible and therefore diminish the importance of it due to the history of many companies and their misconduct in regards to CSR. Companies that communicate about their CSR activities often confront allegations of social irresponsibility. (Vanhamme J., et al., 2015).

Other studies emphasize that the consumers see the true motivation behind CSR as it is largely focused on communicative, relational, and reputational benefits which naturally compromises its morality (Ihlen O., et al., 2011). The authors make the case by saying CSR is only possible where a company's profits will be enhanced: it is impossible to escape the self- interested perspective; 
financial profits are sought at any cost (Ihlen O., et al., 2011). It is possible that this is the reason why some consumers don't see the good in CSR which makes it rather irrelevant for certain amount of consumers.

Also, there are studies that question the difference of values in different cultures, asking does the consumer even value that the company which products he or she is buying contributes to make the world a better place across all cultures? An argument is made that different cultures have different values and some values may exist everywhere, but, even so, there is a difference in ranking priorities of values (Mooij M., 2005).

However, it must be stated that the authors analysed 17 academic articles and 14 books about the subject, and out of all these studies founded in these materials, there were only four studies that did express arguments for lack of significance of Corporate Social Responsibility, which arguably is very little compared to the total amount of studies analysed.

In summation of the literature review, there seem to be an overwhelming conclusion that CSR does work and the consumers are willing to switch products because of CSR, in favour of the companies that are socially responsible. Consumers will switch brands due to the CSR efforts (Mirvis P., 2008). Indeed, evidence is that when a product's social content aligns with their consumers' personal interests; it can be decisive in building brand loyalty (ibid). Not only the consumers will switch to another brand or product due to the CSR efforts, it will also build brand loyalty which is highly important for the brand's personal sustainability in the market.

\section{Methodology of the practical research}

This research focused on qualitative methods by conducting five in-depth interviews with experts of CSR and a focus group with consumers. This was done to ensure meaningful data that would help to understand in-depth the reasons of why consumers prefer or do not prefer socially responsible companies as well as in-depth reasons from the experts of their CSR commitments. The interviews were conducted in both Denmark and Latvia. The focus group was conducted in Denmark. Both, the interviews and focus group were conducted at the end of year 2016.

The in-depth interviews were conducted with five experts in the field of CSR, for instance, sustainability (CSR) manager Fleming Lynge Nielsen of a large Danish company Danfoss. The company Danfoss was chosen due to their CSR efforts that help the community and emphasize their green energy commitments, therefore indicating that they would have a lot of relevant information to share for the purposes of this study. Other interviewees were Povl Schroder who is Senior Director and Head of Group Regulatory at Danfoss, Juste Brukiene who is project manager of sustainability projects at Danfoss, Otilia Dragan who is corporate brand manager at Danfoss. And finally, in order to get a different perspective on CSR, as the fifth expert interviewed for this research was a partner and a strategist of a large advertising agency in Latvia, the ad agency Weekend, Edgars Petersons. As the man who meets with clients and proposes to follow the market tendencies such as CSR, he had valuable insights to provide during the interview about the consumers and companies in regards to CSR efforts.

In order to find out whether consumers appreciate that companies make Corporate Social Responsibility efforts a focus group was conducted. Eight people were selected for this focus group from various countries to ensure a wider representation of backgrounds: Estonia, Denmark, Latvia, the Czech Republic, Slovakia and Lithuania. There were 3 men and 5 women, the participants were not briefed before the focus group to ensure total objectivity of the data and the process. 


\section{Research results of the interviews and the focus group}

Interviews

Prior to the interviews with experts there were several questions that the authors needed to get answers to from a real life business perspective about Corporate Social Responsibility. Up until the interview process the authors only had the theoretical answers from the literature review process. The authors did not let the theory influence the process of the interviews and humbly paid attention to the interviewees, which were the experts within CSR area.

The main question and the most telling about the subject of this research, that the interviewees were asked, was the necessity or the importance of CSR for the consumers. Edgars Petersons answered: "They (consumers) demand more and companies have realized that, so companies are trying to cash in on that. It used to be that a company is giving money to charity and that was it, but now the consumer has also become more cynical and more difficult to convince. So companies now are thinking more of how to integrate CSR in the core of their brand."

A similar opinion is expressed by the other interviewees, which is also found to be true according to the studies in the subject examined during the literature review. Meaning that consumers, indeed, are demanding brands to be more socially responsible and that is shaping their buying behaviour. Therefore the companies are following the demand as a consequence. The interview with Edgars Petersons and other interviewees also reveal another telling key element, that companies have changed their approach of CSR. Companies used to make rather temporarily campaigns or even lesssimply give money to a charity fund. However, now companies have discovered that the consumer sees through the motivation of some companies' CSR activities, which makes them cynical, which is also what the scientific literature suggests. According to the interviewees, this factor has made companies more thorough in their CSR efforts, even more, it has made the companies to put their CSR activities at the core of their brand.

Another relevant question that is worth discussing was about how the companies get the information about the market tendencies particularly the necessity of CSR from the consumer point of view. Fleming Lynge Nielsen said that they are doing a thorough research about the needs of the customer, saying:

"Yes, we are hiring research and consulting companies to get information. We are talking to our peers, business partners and customers. We ask them does this and this make sense to you. We do customer perception studies. We also have students who are doing their PhD projects with relevant research for our company's CSR strategy."

The same is expressed by Juste Brukiene and Otilia Dragan, who concur to Fleming's description of the process of getting vital information about customers' perception of Corporate Social Responsibility. This indicates that the necessity of CSR is very fundamentally established, because the companies do their own research as well, not just rely on the research from the academics and the scientific community, which shows alignment with the results from different areas and make a more compelling argument about the importance of CSR.

And finally, it is vital to know how companies measure the results and do these results confirm the necessity of CSR campaigns? Fleming Lynge Nielsen answered: "We do customer perception studies. We also hire consultants and researchers to help us find out the effect of the campaigns." Otillia Dragan provided a more specific answer saying that: "They (results from the research about CSR campaigns) show improved perception of our company. We see that we have a greater purpose doing what we do." These opinions are also in alignment with Edgars Petersons who suggests that: 
"We can see the tendencies that it (CSR) does give positive platform for the brand and communication, and there are many world-wide studies that prove the fact that CSR is profitable."

Focus group

The main part of the focus group was to find out if the consumers actually value corporate social responsibility, therefore does it even matter from a profit motive for the companies to go the extra mile and be socially responsible for the benefit of the community, the environment and even their own employees. First, starting by asking the respondents a simple question "Does everyone know what is CSR?" As a big surprise for the authors and the moderators of this focus group, the participants nearly unanimously said No, except for one of the respondent: "Company has to have some sort of environmental responsibility. Especially if you are a huge company you should do charity." (Respondent 7) Perhaps it was due to the participants being shy at first, but later, though, the respondents became much more open and energetic, and provided longer and more detailed answers, that were useful for the research. After the first question, the authors explained to the respondents what CSR is, and gave examples of it, which immediately showed understanding in the participants of the focus group. "It sounds so weird. I knew something like this, but did not know that this stands for that term." (Respondent 5)

The term CSR was very unclear to the respondents, and even though they knew CSR activities, they did not know that this phenomenon is called CSR, and certainly they did not know that the word 'Sustainability' stands for CSR (which it does, according to the interviewees and several scientific literature sources): "That is very vague... I associate it to green energy". (Respondent 4) But despite the lack of knowledge about the term CSR, the respondents (consumers) have a very positive attitude towards what CSR actually stands for. For the question "Would you be willing to switch to a product if you found out that the company producing this product does CSR, if the product cost the same compared to the alternative?" The respondents answered unanimously "Yes". To the question "What if the CSR product costs more than the alternative? The answer largely was "Depends": "Depends how much more, and what the product is." (Respondent 2)

A relevant aspect of seeing the value of CSR for the consumers was to find out if the consumer would tell their friends about a certain CSR activity? Because that indicates how relevant the CSR aspect is to the consumers, that they would try to convince their friends and peers about something that they themselves feel strongly compelled to support. And the answer to this vital question was mostly "Yes". The answer was rather cautious in support of telling friends about a certain brand's CSR efforts when it came to posting it on Facebook (sharing a CSR related article, for example). The answers to this question were: "Yes I would tell it. Depends how relevant it is to my friends. Some companies test cosmetics on animals. I have told a friend that." (Respondent 7). Others were a bit more distant into providing a positive answer to the question of whether they would share a CSR article about a brand on their Facebook wall: "It depends on the issue, if it would matter to me than I would" (Respondent 2) And some respondents simply answered with "No" (Respondent 3, Respondent 4, Respondent 6).

The focus group really became live on the question "Does your favourite brand/ product is involved in CSR?" The answers provided became more than just about favourite brands and CSR but the use of CSR for the companies in general.

"I would not know it unless I checked." (Respondent 6). Another respondent answered: "Many big corporations do not do CSR, like Calvin Klein" (Respondent 7). However, perhaps the most telling comment came from Respondent 2, saying that: "In the production line they do some really messed 
up things, and then later they give money to charity, to make up for it (production)." This cynicism speaks directly to the research results from the interviews as well as what the scientific literature suggest, that consumers often see CSR as an escape from the social irresponsibility, as a means to make up for the enormous mistakes made in the community or in regards to the environment. It therefore suggest that companies should be careful not to come off as disingenuous, but be sincere in their CSR efforts. Another respondent concurred to this same thought, saying that: "They are saving environment by giving you paper bag instead of plastic bag, even though they really screw up before (environmentally)." (Respondent 6)

However, there was an answer that provided a fair and balanced view on companies that make CSR efforts: "It is definitely not black or white issue. There are some companies that genuinely try to be as good as possible, but of course there are companies who only do it for profit or to cover up their lack or social responsibility." (Respondent 7) This opinion shows that while there are companies that deserve a cynical view from the consumers about their CSR activities, there are also that sincerely are caring about the community, their employees, the environment and the society in general.

There was also a specific example mentioned in the focus group discussion, particularly talking about the companies that are likeable due to their CSR efforts: "But we learned about Innocent- they build their company based on a model that they only used fresh fruit, and give money to charity." (Respondent 6) This opinion that was echoed by others in the focus group shows that consumers are aware of the companies being socially responsible and appreciating it. Another company that was mentioned during this part of the focus group was Danfoss as also one of the companies being socially responsible. Although, in fairness, it could be because it is one of the largest companies in Southern Denmark. However, it still shows awareness for CSR activities of Danfoss that in this case is directly linked with likeability, which shows the importance of CSR. It was also observed that nationality of the participants of the focus group did not play a role in their responses to the questions and the process in general.

\section{Conclusions, proposals, recommendations}

1) The literature review combining many studies on the matter of CSR strongly confirm the importance of CSR for the consumers which is in alignment with the rest of the research. There is an overwhelming evidence of Corporate Social Responsibility is very important in the eyes of today's consumer. That was expressed by the experts of the CSR and marketing industry who are dealing with CSR campaigns. It was also evident by the focus group providing answers to questions about the relevance of CSR in their purchases and views on CSR driven brands in general.

2) Consumers often are quite skeptical and cynical due to companies that only follow CSR practices after being caught of being involved in wrong doing and being socially irresponsible, therefore the CSR campaigns and efforts have to be genuine, not as means to correct past mistakes.

3) Companies should embed CSR at the core of their brand and make their activities fundamental, continuous and not just temporary campaigns and a one- time donations to a charity organization, which might seem disingenuous in the eyes of the consumer. 


\section{Bibliography}

1. Coombs, W., Holladay, S. (2012); Managing Corporate Social Responsibility- A Communication Approach. Malden: Blackwell Publishing.

2. Diehl, S., Terlutter, R., Mueller, B., (2016); Doing Good Matters to Consumers: the Effectiveness of Humane-Oriented CSR Appeals in Cross-Cultural Standardized Ddvertising Campaigns. International Journal of Advertising. 35:4, 730.-757.

3. Ihlen, O., Bartlett, J., May, S. (2011); The Handbook of Communication and Corporate Social Responsibility. Malden: John Wiley \& Sonds, Inc.

4. May, S., Cheney, G., Roper, J. (2007); The Debate Over Corporate Social Responsibility. New York: Oxford University Pres, Inc.

5. Mirvis, p. (2008); Can You Buy CSR? Journal of California Management Review, Vol. 51, No. 1. Fall. Page 109.-115.

6. Mogele, B., Tropp, J. (2010); The Emergence of CSR as an Advertising Topic: A Longitudinal Study of German CSR Advertisements. Journal of Marketing Communications Vol. 16, No. 3, July 2010, 163.-181.

7. Mooij, M. (2005); Global Marketing and Advertising- Understanding Cultural Paradoxes. London: Sage Publications.

8. Sohn, Y., Han, J., Lee, S. (2012); Communication Strategies for Enhancing Perceived Fit in the CSR Sponsorship context. International Journal of Advertising, 31(1), pp. 133.-146.

9. Vanhamme, J., Swaen, V., Berens, G., Janssen, C. (2015); Playing With Fire: Aggravating and Buffering Effects of ex Ante CSR Communication Campaigns for Companies Facing Allegations of Social Irresponsibility. Mark Lett, 26:565.-578.

10. Watt, K., (2010); The Future of Sponsorship Integrated With CSR/CSI Strategy. Journal of Sponsorship. VOL. 3. NO. 3. 220.-227. MAY 2010 